\title{
A Review of Open-Ended Mathematical Problem
}

\author{
Lim Keng Keh \\ Universiti Teknologi Malaysia, kklim6@live.utm.my \\ Zaleha Ismail \\ Universiti Teknologi Malaysia,drzaleha2@yahoo.com \\ Yudariah Mohammad Yusof \\ Universiti Teknologi Malaysia, yudariah@utm.my
}

This paper aims to understand the use of open-ended mathematical problem to stimulate students' ability in problem solving. There were five mechanical engineering participating in this study. Their works were video-taped as to reveal their process of problem solving. Intervention of creative problem solving was used as to help the students to come out with solutions. They were also interviewed individually after they had solved the problem. All the process of problem solving and their conversations were video-taped and audio-taped, transcribed and then analyzed into sub-themes, namely: problem definition, ideas generation, ideas evaluation, ideas judgment, and solution implementation. Questionnaire was also distributed to three classes of 74 mechanical engineering students as to find out their preference in all the stages of creative problem solving. The result showed that the students were able to solve the open-ended mathematical problem collaboratively based on all the stages of creative problem solving..

Key words: open-ended mathematical problem, creative problem solving, problem solving, creativity, mathematical problem.

\section{INTRODUCTION}

Typical students have some misconceptions about the nature of mathematical problems. They believe that mathematical problem has one and only one correct solution (Lampert, 1990). Mathematical problems which have only one correct answer will discourage students to use their diverse ideas to find out the answer (Kwon \& Park, 2006). Wu (1994) said that traditional mathematical problems allow students to obtain only one correct solution and this is too rigid for the students to show their understandings in mathematical problem solving. Therefore, most students faced a great difficulty when they came across open-ended mathematical problems. Foong (2002) also stated that open-ended problems are ill-structured and there are many missing data and therefore there is no fixed procedure to guarantee to get a correct solution . In fact, there are more than one solution for these types of problems and students can use

Citation: Keh, L. K., Ismail, Z., \& Yusof, Y. M. (2016). A Review of Open-Ended Mathematical Problem. Anatolian Journal of Education, 1(1), 1-18. https://doi.org/10.29333/aje.2016.111a 
multiple approaches to solve the problems with little constraints on their methods using (Hancock, 1995). Kwon and Park (2006) also said that open-ended mathematical problems can encourage students to use multiple approaches to find a solution for their problem base on their own scope and mathematical abilities. In the process of problem solving, students can discuss their solutions with diverse inferences and this will also cultivate their mathematical communication skills (Kwon \& Park, 2006). According to Sullivan (2006), open-ended mathematical problems can also help students to engage in their active learning and construct their own mathematical knowledge. Capraro and Cifarelli (2007) mentioned that open-ended mathematical problems can allow students to use different strategies to obtain their solutions and this gives them the opportunity of developing their mathematical understandings and skills.

Schoenfeld (1983) revealed one of the goals in the mathematical problem solving courses is to train the students to solve mathematical problems creatively with heuristic strategies and also using new approach with critical thinking skills. Perveen, (2010) also showed that by using Polya's (1945) heuristic strategies and Sherreen's (2006) guideline as the approach for problem solving can help students to improve their mathematical achievements compared with the use of expository strategy. According to Bay (2000), the teaching of heuristic strategies can be used as the teaching of problem solving in order to solve mathematical problems. Skinner (1984) stated that problem solving can be defined as the framework for creative thinking and learning of mathematics.

Mathematics problems can be solved in my different ways and from different approaches; some problems have even more than one solution. For example, we can solve simultaneous equations by using substitution, elimination; by using graph and also by using matrices. Chinese mathematician "Chang Chiu Chen" in the sixth century once gave a famous mathematics problem "Hundred Fowls" and students can use many approaches to solve this problem; for example, they can solve the problem algebraically, by trial and error; by using table or graph. There was also more than one solution for this problem and students can use their own interpretation to make sense of the problem. At the end of solving this type of ill-defined problem, the students can develop their creativity in the features of fluency, flexibility and novelty. Students were also given more freedom, openness and selection to solve mathematics problems and they were motivated to become more independent and self-confident in the process of learning mathematics (Silver, 1997). 


\section{METHOD}

The famous mathematical problem "Hundred Fowls" which stated that : "If you are offered to buy a rooster with five coins, a hen with three coins and three chicks with only one coin. How many roosters, hens and chicks can be bought with only 100 coins and you can only buy altogether 100 of them?" This mathematical problem was used in this research.

Intervention of creative problem solving was used as to help the students to come out with creative solutions. Five mechancal engineering students took part in this study and they were also interviewed individually after they had solved the open-ended mathematical problem. All the process of their problem solving and conversations were video-taped and audio-taped, transcribed and then analysed into sub-themes, namely: problem definition, ideas generation, ideas evaluation,ideas judgment and solution implementation.

Questionnaires were also distributed to three classes of 74 mechanical engineering students in the local university. Five-points Likert scale was used as to find out the means, standard deviations and standard error means in all the categories of items. There were altogether 43 items in five categories. Each item was set against a five-point Likert scale of "strongly disagree", "disagree", "neither", "agree" and "strongly agree" with weights of 1,2,3,4 and 5. The students were allowed to pick one of them as to show their favourable selections. The data were then collected and analysed by using SPSS as to find out what did the students do in all the stages of creative problem solving. The three hignhest means in each category were obtained as to find out the preference of the students in every stage of creative problem solving.

Questionnaire, observation and interview were used to triangulate all the data collected in this study.

\section{FINDINGS}

\section{Problem Definition}

From the table I, the first category of the result showed that as the students before they started to solve the problem, first they will identify all the relevant information such as all the data and condition of the problem in order to define the problem. They also would like to find out all the unknowns and variables in the problem as to help them to find out whether there was enough information to solve the problem. 
Table 1

\begin{tabular}{ll|l|c|c}
\multicolumn{2}{l}{$\begin{array}{c}\text { Problem Definition } \\
\end{array}$} & Mean & Std. Deviation & Std. Error Mean \\
\hline $\mathrm{A} 1$ & 74 & 4.15 & .932 & .108 \\
\hline $\mathrm{A} 2$ & 74 & $3.91^{*}$ & .924 & .107 \\
\hline $\mathrm{A} 3$ & 74 & 3.69 & 1.122 & .130 \\
\hline $\mathrm{A} 4$ & 74 & 3.92 & .754 & .088 \\
\hline $\mathrm{A} 5$ & 74 & $3.91^{*}$ & .779 & .091 \\
\hline $\mathrm{A} 6$ & 74 & 3.66 & .880 & .102 \\
\hline $\mathrm{A} 7$ & 74 & 3.72 & .852 & .099 \\
\hline $\mathrm{A} 8$ & 74 & 3.73 & .926 & .108 \\
\hline $\mathrm{A} 9$ & 73 & 3.70 & .996 & .117 \\
\hline $\mathrm{A} 10$ & 72 & 3.56 & .963 & .113 \\
\hline
\end{tabular}

Note

Item A1 - I identify all the relevant information.

Item A2 - I find out whether there is enough information to solve the problem.

Item A3 - I highlight the key terms.

Item A4 - I find out all the unknowns and variables in this problem

Item A5 - I find out all the data and condition (constraint of the problem).

Item A6 - I separate the different conditions

Item A7 - I find out whether the condition is sufficient to determine the unknown.

Item A8 - I define all the unknown with suitable notation.

Item A9 - I relate all the unknown with equations or formula.

Item A10- I introduce notation or symbol.

From the table, we found out that the three items with the highest means were items A1, A4 and A2/A5 (A2 and A5 had the same mean.) 
From the first movie clip, one of the students showed that they can suggest a way to define the problem before solving it.

Student Yap: "How about we list out all the restriction and limitation so that we can see the problem clearer."

Student Goh indicated that the number of unknown of the problem.

He said: "But there is three unknowns. So, it should form at least one more equation to solve simultaneous."

Student Yap suggested another way to define the problem.

He said: "The first is that the number should not, should be whole number.. ..Can not be with that ..decimal.....integer."

From the interview, we found out that students first read the problem and understand it before they identified all the unknowns such as fact, data or information in order to develop their solutions.

"Okay, first read the question and understand the question roughly and then, okay we need to identify all the information given, the unknown, how many equation can form." (Student Yap from interview)

Then, they listed out all the fact, data and information to find out the restrictions. They inspected what the question needed and list out all the questions asked in order to solve the problem.

"Okay, first I will read the question first and then I will identify all the unknown, unknown variable, unknown variable inside the question that it will list out all of it and then I will look at the question and we will. I will develop some equations that it will lead to the situation of the solution like....solution." (Student See from interview).

\section{Ideas Generation}

The table II showed that as the students worked on the problem, they would find out the connection between the unknown and the data in order to generate ideas to solve the problem. They also craeted an organized list of ideas at this stage. They checked whether they had used up all the data and condition for them to solve the problem.

Table 2

Idea Generation

\begin{tabular}{cc|c|c|c} 
& & & \\
& $\mathrm{N}$ & Mean & Std. Deviation & Std. Error Mean \\
\hline B1 & 74 & 3.59 & .890 & .103 \\
\hline
\end{tabular}




\begin{tabular}{ll|l|l|l}
\hline B2 & 74 & 3.58 & .993 & .115 \\
\hline B3 & 71 & 3.76 & .902 & .107 \\
\hline B4 & 74 & 3.46 & .982 & .114 \\
\hline B5 & 74 & 3.50 & .910 & .106 \\
\hline B6 & 73 & 3.26 & 1.028 & .120 \\
\hline B7 & 73 & 3.36 & .991 & .116 \\
\hline B8 & 74 & 3.72 & .944 & .110 \\
\hline B9 & 74 & 3.69 & .905 & .105 \\
\hline B10 & 74 & 3.74 & .861 & .100 \\
\hline
\end{tabular}

Note

Item B1 - I generate many ideas(fluency), varied ideas (flexibility) and unusual ideas(originality)

Item B2 - I analyse and review data.

Item B3 - I find the connection between the unknown and data.

Item B4 - I restate the problem and make it simple.

Item B5 - I find out many ideas to solve the problem by using brainstorming,

analogy or cross-fertilization

Item B6 - I try to solve the problem by using diagrams, tables, or graphs.

Item B7 - I play with the data by increasing or reducing certain part to come out with new ideas.

Item B8 - I create an organized list of ideas.

Item B9 - I check whether have used up all the data.

Item B10- I check whether have used up all the condition.

From the table, we found out that the three items with the highest means were items B3, $\mathrm{B} 8$ and $\mathrm{B} 10$.

The next movie clip revealed that student can generate many other ideas in order to find a method to solve the problem. They used three different methods to solve the problem. 
The first method used was trial and error or inspection. The second method used was graph and the last method was computer programming.

Student Yap suggested using trial and error to solve the problem.

He said: "I think the only way we can find is by inspection or trial and error. " "Then, we set the question first, then we can get the third equation or may be eliminate at least one unknown. For example, may be, we can set the chick equal to zero. So C equal to zero. Then try to solve it. If C equal to zero."

"I got the two. Okay, so we can let $C$ equals to zero, right? So, if $C$ equals to zero, so we get the equation of five $R$ plus three $H$ equals to one hundred. And $R$ plus $H$ equals to one hundred. So, multiply by three, equation two.... "

"Ha.. R equals to zero, so you get three H plus one over three equals to one hundred. And H plus C equals to one hundred. This side is correct."

Student Goh used graph to help him to solve the problem. He drew axis and a straight line on the white board in order to figure out the problem.

Student Chai suggested student Goh to solve the problem with new idea:" Why don't you do like this, let $R$ and $H$ equals to zero, then we can see what position at axis. Let $R$ and $H$ be zero."

Student See suggested using computer programming to solve the problem.

He said: "Like a.. my answer before this when we learn about programming. So what about we just use programming, program and code to trial and error for us."

From the interview transcripts, it showed that students discussed among themselves in a group to generate ideas to solve the problem. They used brainstorming and find out a better way to solve the problem by accepting only good ideas and even correct other ideas. They wrote down their ideas on paper.

"How do I generate? Ah.... a. create ideas ..... I brainstorm.....brainstorming with my friends, then we gather all the ideas and review the ideas and theory we have discuss and then collect the good one and leave the bad one." (Student Goh from interview).

Student See suggested others to solve the problem by using programming. He said: "How about you try in another method? We do this trial and error in another method?" He generated new ideas to solve the problem by using programming. (Student See from interview).

\section{Ideas Evaluation}

The third category of the data in table III showed that after the students had solved the problem, they would examine the solution obtained and also checked the result and the argument. The students would also check whether their solutions satified all the 
conditions in the problem. They also generalized the solutions for the problem so that they could use it for the similar problem as they would encounter in the future.

Table 3

Ideas Evaluation

\begin{tabular}{ll|c|c|c} 
& $\mathrm{N}$ & Mean & Std. Deviation & Std. Error Mean \\
\hline $\mathrm{C} 1$ & 74 & 3.57 & .923 & .107 \\
\hline $\mathrm{C} 2$ & 74 & 3.82 & .912 & .106 \\
\hline $\mathrm{C} 3$ & 74 & 3.41 & .792 & .092 \\
\hline $\mathrm{C} 4$ & 74 & 3.82 & .881 & .102 \\
\hline $\mathrm{C} 5$ & 74 & 3.97 & .860 & .100 \\
\hline $\mathrm{C} 6$ & 74 & 3.80 & .876 & .102 \\
\hline $\mathrm{C} 7$ & 74 & 3.89 & .786 & .091 \\
\hline $\mathrm{C} 8$ & 74 & 3.80 & .965 & .112 \\
\hline $\mathrm{C} 9$ & 74 & 3.73 & .880 & .100 \\
\hline $\mathrm{C} 10$ & 74 & 3.74 & .861 & .098 \\
\hline $\mathrm{C} 11$ & 74 & 3.91 & .847 & \\
\hline
\end{tabular}

Note

Item C1- I use second round of brainstorming by focusing on the practical ideas to be implemented.

Item C2 - I evaluate ideas based on criteria.

Item C3 - I rank a list of ideas based on their pros and cons.

Item C4 - I examine the solution obtained.

Item $\mathrm{C} 5$ - I check the result.

Item C6 - I check the argument

Item C7 - I check whether the solution satisfy all of the given conditions in the problem.

Item C8 - I check whether the answers make sense.

Item C9 - I check whether it answers all parts of the question.

Item C10-I recheck any computations made while finding the answer for errors. 
Item C11-I generalize the solution for this problem so that it can be used for the similar problem in the future.

From the table, we found out that the three items with the highest means were items C5, $\mathrm{C} 7$ and $\mathrm{C} 11$.

In this stage, the observation transcipts showed that the students justified their answers and checked whether their solutions made sense.

Student Yap said:" Seventy eight divided by three .. twenty six.. so the second answer is correct, how about the third one?"

Student Yap said: "Wait, we still need to measure that the sum of the .. sum of the fowls are ..." "Seventy eight divided by three .. twenty six.. so the second answer is correct, how about the third one?"

Student See said: "If integer, it fulfils that two equations."

From the interview transcripts, the results showed that the students evaluated their answer by substituting it into the equations to make sure the answer is valid.

"I basically check my result based on the, based on the problem and sometime I will check the answer whether it is valid or not. If the question asks for real number, then my answer is not real number, then my result is wrong. I can know my result is wrong." (Student See,from interview).

"We actually sub. in the..er............the answer we got.to redo it so that the right hand side is equal to the left hand side which means. ....... equation and the answer is valid itself". (Student Lee, from interview).

The students worked backward in order to check whether the answer makes sense, whether the answer meets the limitation and restriction. They also checked one by one for any error in the equation.

"I substitute it all the answer inside the equations. So, if the, if the answer in the left hand side of the equation and the answer in the right hand side of the equation is the same one, then it is correct. And then we will check the sign, positive, negative and if got right, wrong or not." (Student See from interview).

"Counting from the back, backward method like .., working backward to get the answer." (Student Lee from interview).

\section{Ideas Judgment}

The next category of data in table IV showed that students would make their decisions and selected the best solution for their problem based on their judgment. They also 
justified the reasons to select the solution as the best method to solve the problem. They eliminated all the impractical ideas or modified them to become more practical.

Table 4

Ideas Judgment

\begin{tabular}{l|c|c|c|c} 
& $\mathrm{N}$ & Mean & Std. Deviation & Std. Error Mean \\
\hline $\mathrm{D} 1$ & 74 & 4.04 & .883 & .103 \\
\hline $\mathrm{D} 2$ & 74 & 3.99 & .852 & .099 \\
\hline $\mathrm{D} 3$ & 74 & 3.77 & .884 & .103 \\
\hline $\mathrm{D} 4$ & 74 & 3.91 & .878 & .102 \\
\hline $\mathrm{D} 5$ & 74 & 3.97 & .776 & .090 \\
\hline D6 & 74 & 3.93 & .800 & .093 \\
\hline
\end{tabular}

Note

Item D1 - I decide to select the suitable method to solve the problem based on judgment

Item D2 - I justify the reason to select it as the best method.

Item D3 - I select best ideas to be implemented

Item D4 - I look at the criteria to make a final choice

Item D5 - I eliminate impractical ideas or modify it to become practical.

Item D6 - I defer judgment and benefits of using it.

From the table, we found out that the three items with the highest means were items D1, D2 and D5.

The following observation transcripts revealed that student made decision to select the best method to solve the problem. They drew tables and voted for their selection and also gave reason for their selections.

Student Lee believed that drawing graph can help him to solve the problem, he said: "Because, er.. I think when we draw a graph, we see clearly, and we can get a clearer picture of it."

Student Yap first selected trial and error as the best method to solve the problem: "I think trial and error is then a good choice to solve this problem." 
Finally, Student Yap also agreed to select computer programming as the best method, he said: "I agree with their opinions, because is the fastest way, and you can find out all possible answer for that question."

The interview transcripts showed that students first devised a table and then listed out all the possible method to solve the problem in order to find out the best solution to solve the problem.

"Okay... just like mm....may be, we can devise a table, then list out all the possible method to solve the problem, then write down the pros and cons of using those methods, then vote for all the method and the highest mark.." (Student Goh from interview).

Then, they listed out all the cons and pros of using these methods and compared the different methods based on efficiency, accuracy, flexibility, simplicity, originality, convenient and time saving.

"Okay, first, we will do the question, different solution first, method first and then we will compare with each other. We discuss about it. So, we think that which one is the easiest one. Which one is the fastest one and the most efficient one, then we will select the one which are, are...., the best one, the best solution. The fastest solution and the efficient solution." (Student See from interview).

Then, they identified the method to solve the problem and selected the best method by voting.

"Okay....I think we will vote it. Voting, by voting...are...., So......ar. We will leave out the method first and we will vote. We get the most number of voting that is the decision we make." (Student See from interview).

\section{Solution Implementation}

The last category of data as showed in Table $\mathrm{V}$ indicated that after the students had solved the problem, they would examine the solution obtained and also checked the result and the argument. The students would also check whether their calculations were correct in each steps as they carrying out their plan.

Table 5

Solution Implementation

\begin{tabular}{cc|c|c|c} 
& $\mathrm{N}$ & Mean & Std. Deviation & Std. Error Mean \\
\hline E1 & 74 & 3.58 & .876 & .102 \\
\hline E2 & 74 & 3.93 & .782 & .091 \\
\hline
\end{tabular}




\begin{tabular}{lllll}
\hline E3 & 74 & 4.04 & .801 & .093 \\
\hline E4 & 74 & 3.97 & .776 & .090 \\
\hline E5 & 74 & 4.01 & .785 & .091 \\
\hline E6 & 74 & 3.61 & .963 & .112 \\
\hline
\end{tabular}

Note

Item E1 - I prove that the answers are correct.

Item E2 - I carry out the plan that has been chosen.

Item E3 - I explain clearly for carrying out the steps.I justify the reason to select it as the best method.

Item E4 - I check each steps carefully.

Item E5 - I check to see whether each step is correct.

Item E6 - I justify my answers.

From the table, we found out that the three items with the highest means were items E3, E4 and E5

The last observation transcripts showed that student implemented and came out with a solution. They also checked each step carefully in the process of problem solving.

Student Goh said: "I change to my $X$,three $X$ plus three $Y$ plus three $Z$ equals to one hundred, the second equation is X plus Y plus Z equals to one hundred." "What, if you put $y$ equals to $Z$ is equals to zero, then $x$ is equals to hundred. Let $Y$ equals to zero, $X$ is equals to hundred, $x$ equals to zero, $y$ equals to..." "So the range for the C must be within zero to one hundred. Must be multiplier of three."

Student Yap said: "Then $x$ plus y should be.., because we have chicken already.. er, chicks already eighty one.. so nineteen .. nineteen ... seventy six minus four y plus two $y$ ,..,

From the interview transcripts, it showed that students implemented the solution by listing out all the solution so that they can transform their ideas into practical solution. They solved the problem by drawing a graph, calculating on paper or running a programme. They can even use their imagination to assume that the problem as the real world problem.

"Okay, we will come up with paper first and then list out all the, list out all the solution 
and then if the question needed, ar..... to draw a graph., we draw a graph. And then calculating, we work it on the paper, ar...., then we get the answer." (Student See from interview).

"Transfer,.......... for example, we select like the programming, then we .. you know, .with the equation we get, actually involve both the simultaneous and the trial and error if we use the programming method, then we try to design our code." (Student Yap from interview).

"I transform the idea like a.....like I don't do, I don't like solve the problem basically by using the theory that I have learnt. Sometime, I will just like .......ah....... like imagine that problem into the real, the real world problem and then I solve it by, solve it by my idea." (Student See from interview).

\section{Triangulation of data}

The collected data form questionnaire, interview and observation were triangulated as below.

Table 6

Triangulation of Data

Stage 1: Problem Definition

\begin{tabular}{|c|c|c|c|}
\hline From Questionnaire & From Interview & From Observation & Triangulation \\
\hline $\begin{array}{l}\text { 1. Identify all the } \\
\text { relevant } \\
\text { information. } \\
\text { 2. Find out whether } \\
\text { there is enough } \\
\text { information to } \\
\text { solve the } \\
\text { problem. }\end{array}$ & $\begin{array}{l}\text { 1. Identify all the } \\
\text { unknowns to } \\
\text { develop the } \\
\text { solution. } \\
\text { 2. Read the problem } \\
\text { and understand it }\end{array}$ & $\begin{array}{l}\text { 1. List out all the } \\
\text { restriction and } \\
\text { limitation to make } \\
\text { the problem } \\
\text { clearer. } \\
\text { 2. Suggest ways to } \\
\text { define the } \\
\text { problem. }\end{array}$ & $\begin{array}{l}\text { In the first stage, the } \\
\text { students would define } \\
\text { the problem by } \\
\text { finding out all the } \\
\text { information in order } \\
\text { to help them to solve } \\
\text { it. }\end{array}$ \\
\hline
\end{tabular}

3. Find out all the unknowns and variables in this problem.

4. Find out all the data and condition (constraint of the problem). 
Stage 2: Ideas Generation

\begin{tabular}{|c|c|c|c|}
\hline From Questionnaire & From Interview & From Observation & Triangulation \\
\hline $\begin{array}{l}\text { 1. Find the } \\
\text { connection } \\
\text { between the } \\
\text { unknown and } \\
\text { data. }\end{array}$ & $\begin{array}{l}\text { 1. Discuss among } \\
\text { themselves in } \\
\text { order to generate } \\
\text { ideas to solve the } \\
\text { problem. }\end{array}$ & $\begin{array}{l}\text { 1. Generate many } \\
\text { ideas to solve the } \\
\text { problem. } \\
\text { 2. Generate } \\
\text { alternative ways }\end{array}$ & $\begin{array}{l}\text { In the second stage, } \\
\text { the students would } \\
\text { discuss and generate } \\
\text { many ideas to solve } \\
\text { the problem. }\end{array}$ \\
\hline $\begin{array}{l}\text { 2. Create an } \\
\text { organized list of } \\
\text { ideas. } \\
\text { 3. Check whether } \\
\text { have used up all } \\
\text { the condition. }\end{array}$ & $\begin{array}{l}\text { 2. Use brainstorming } \\
\text { to come out with } \\
\text { alternative ideas. }\end{array}$ & $\begin{array}{l}\text { to solve the } \\
\text { problem such as } \\
\text { using trial and } \\
\text { error, using } \\
\text { graph and } \\
\text { computer } \\
\text { programming. }\end{array}$ & \\
\hline
\end{tabular}

Stage 3: Ideas Evaluation

\begin{tabular}{|c|c|c|c|}
\hline From Questionnaire & From Interview & From Observation & Triangulation \\
\hline $\begin{array}{l}\text { 1. Check the result. } \\
\text { 2. Check whether } \\
\text { the solution } \\
\text { satisfy all of the } \\
\text { given conditions } \\
\text { in the problem. } \\
\text { 3. Generalize the } \\
\text { solution for this } \\
\text { problem so that it } \\
\text { can be used for } \\
\text { the similar } \\
\text { problem in the } \\
\text { future. }\end{array}$ & $\begin{array}{l}\text { 1. Substitute the } \\
\text { answers into the } \\
\text { equations to } \\
\text { check whether it } \\
\text { is valid. } \\
\text { 2. Work backwards } \\
\text { to check the } \\
\text { solutions. }\end{array}$ & $\begin{array}{l}\text { 1. Justify their } \\
\text { answers } \\
\text { 2. Check whether } \\
\text { their solutions } \\
\text { make sense. }\end{array}$ & $\begin{array}{l}\text { In the third stage, the } \\
\text { students evaluate } \\
\text { their solution by } \\
\text { working backwards, } \\
\text { substitute their } \\
\text { answers into the } \\
\text { equations and also } \\
\text { justify their solutions. }\end{array}$ \\
\hline \multicolumn{4}{|l|}{ Stage 4: Ideas Judgment } \\
\hline From Questionnaire & From Interview & From Observation & Triangulation \\
\hline $\begin{array}{l}\text { 1. Decide to select } \\
\text { the suitable } \\
\text { method to solve } \\
\text { the problem } \\
\text { based on } \\
\text { judgment } \\
\text { 2. Justify the reason } \\
\text { to select it as the } \\
\text { best method. }\end{array}$ & $\begin{array}{l}\text { 1. Use a table to list } \\
\text { out all their } \\
\text { solutions with } \\
\text { pros and cons. } \\
\text { 2. Select their best } \\
\text { solutions by } \\
\text { voting. }\end{array}$ & 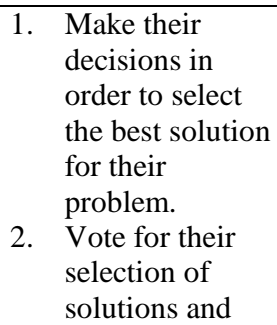 & $\begin{array}{l}\text { In the fourth stage, } \\
\text { the students would } \\
\text { make their decisions } \\
\text { to vote and select the } \\
\text { best the solution to } \\
\text { their problem. }\end{array}$ \\
\hline
\end{tabular}




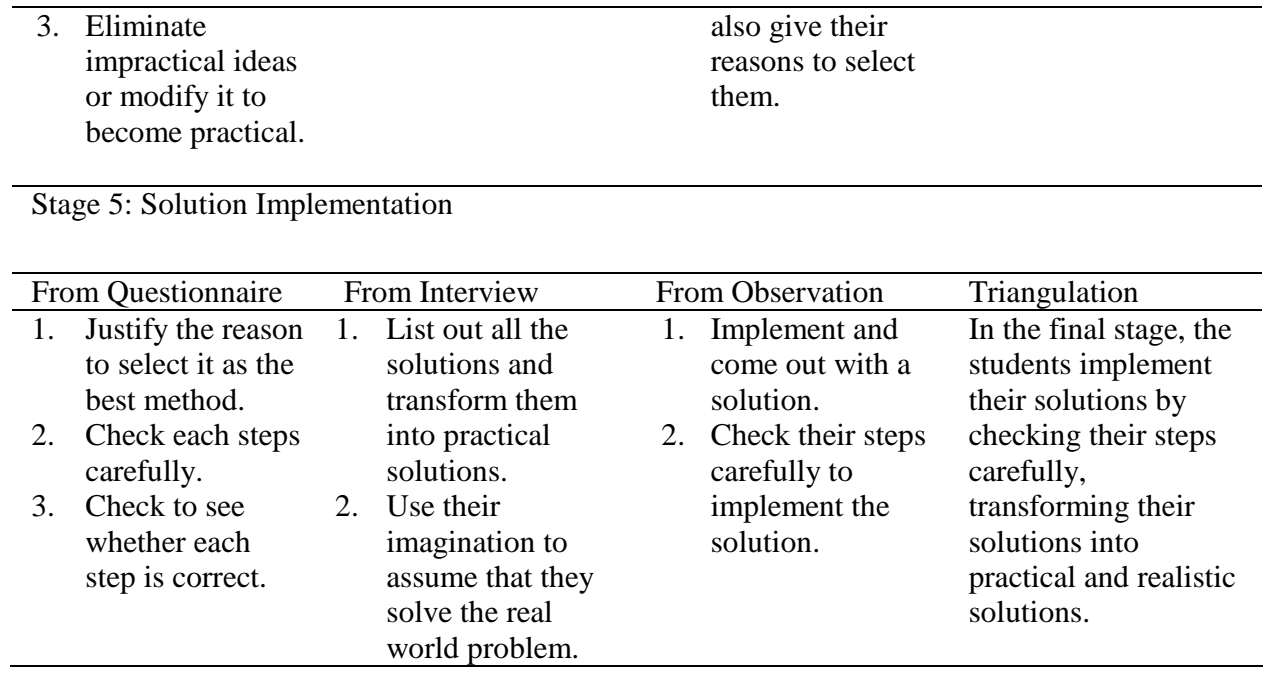

\section{CONCLUSION, DISCUSSION AND SUGGESTIONS}

The result showed that this mathematical problem is ill-structured as we could use different methods or mathematical rules and concepts to solve the problem. We could even use computer programming to solve the problem as long as we justified our answers at the end of problem solving.

Yee (2002) considered open-ended problems as ill-structured problems and they lacked of sufficient data and standard procedures to find a correct answer for the problems. However, real world problems were actually made up of open-ended problems. This required students to foster their higher order thinking skills to create solutions for their problems (Dyer \& Moynihan, 2000). The students had to solve the problems by using their mathematical knowledge and also creative thinking skills. According to Klavir and Hershkovitz (2008), open-ended mathematical problems could even help students to deepen their mathematical understandings and developed their mathematical thinking by learning how to use different strategies to solve open-ended mathematical problems. The students could solve the same type of problems according to their abilities and thus it would release their creative thinking skills.

According to Byun and Lee (2014) there were many definitions for ill-structured problem. Kim and others (2011) defined it as the problem with authenticity, openness and complexity. Authenticity indicated that the problem have to be related to daily life context, openness with many solutions, solution paths or even no solution at all and also complexity of using rules, principles and concepts to solve the problems. Shekoyan and 
Etkina (2007) stated that there were few characteristics for ill-structured problem such as there were uncertainty of using any concepts, principles and rules to solve the problem, many possible paths to solve the problem and also many criteria to evaluate its solutions.

This research enabled us to apply CPS skills to solve open-ended mathematical problems as to foster creativity among the students. There were also many benefits of using CPS such as encouraged dynamic balance between critical and creative thinking; stimulated effective teamwork and cooperation; focused our attention in a correct direction; framed our problems by building motivation and commitment (Isaksen, Dorval \& Treffinger, 2011). It enabled us to stretch our imagination and stimulated many unusual creative ideas to solve a problem and also helped us to turn our creative ideas into workable and usable solutions (Isaksen, Dorval \& Treffinger, 2011). CPS could help us to understand our goals and avoided us from being distracted by many opportunities and challenges in a new situation and thus it could provide a flexible framework to organize tools and strategies to solve a problem (Isaksen, Dorval \& Treffinger, 2011).

Constructivism was used as the theoretical framework in this research as students could actively construct their own mathematical knowledge and made sense of mathematical concepts and thus developed their problem solving skills during the process of social interaction with their peers. In the process of creative problem solving, they also had to depend on the helps of other in order to come out with many creative ideas with the use of group discussion and brainstorming. They could discuss and interpreted their previous experience in solving the problems based on their existing knowledge. Thus, constructivism used in the process of creative problem solving could create a learning environment to develop mathematical creativity and problem solving skills. In this research, the students were able to apply all the stages of creative problem solving, namely: problem definition, ideas generation, ideas evaluation, ideas judgment and solution implementation as they came out with their alternative ideas to solve openended mathematical problem. This was in line with the all stages of creative problem solving from Lumsdaine (2007).

\section{REFERENCES}

Basadur, M. (1995). Optimal ideation-evaluation ratios. Creativity Research Journal, $8(1), 63-75$.

Bay, J. (2000). Linking Problem Solving to Students Achievement in Mathematics Issues and Outcomes. www.nca casi.org/JS1/2000V112/ Problem.solv3-32K 
search on 24-11-2006.

Byun, J. N., \& Lee, W. G. (2014). Development of Ill-Structured Problems for Elementary Learners to Learn by Computer-Based Modeling Tools. International Journal of Computer Theory and Engineering, 6(4), 292.

Capraro, M. M., Capraro, R. M., \& Cifarelli, V. V. (2007). What are students thinking as they solve open-ended mathematics problems. In Proceedings of the ninth international conference of Mathematics Education in a Global Community. Charlotte, $N C$.

Dyer, M., \& Moynihan, C. (2000). Open-ended question in elementary mathematics instruction \& assessment. Eye on Education.

Foong, P. Y. (2002). The role of problems to enhance pedagogical practices in the Singapore. The Mathematics Educator, 6(2), 15-31.

Giangreco, M. F., Cloninger, C. J., Dennis, R. E., \& Edelman, S. W. (1994). Problemsolving methods to facilitate inclusive education. Creativity and collaborative learning: A practical guide to empowering students and teachers, 321-346.

Hancock, C. L. (1995). Implementing the Assessment Standards for School Mathematics: Enhancing Mathematics Learning with Open-Ended Questions. Mathematics Teacher, 88(6), 496-99.

Isaksen, S. G., Dorval, K. B., \& Treffinger, D. J. (2011). Creative approaches to problem solving: A framework for change. Kendall Hunt Publishing Company.

Klavir, R., \& Hershkovitz, S. (2008). Teaching and evaluating 'openended'problems. International Journal for Mathematics Teaching and Learning, 20(5), 23.

Kim, M. K., Lee, J., Hong, J. Y., \& Kim, E. K. (2011). A study of'Ill-Structured'status from mathematics problems in elementary school textbooks. Journal of Learner-Centered Curriculum and Instruction, 11(2), 1-21.

Kwon, O. N., Park, J. H., \& Park, J. S. (2006). Cultivating divergent thinking in mathematics through an open-ended approach. Asia Pacific Education Review, 7(1), 51-61.

Lampert, M. (1990). When the problem is not the question and the solution is not the answer: Mathematical knowing and teaching. American educational research journal, 27(1), 29-63.

Lumsdaine, E. (2007). Creative Problem Solving in Capstone Design. In Proceedings of the American Society for Engineering Education Annual Conference.

Perveen, K. (2010). Effect of the problem-solving approach on academic achievement of students in mathematics at the secondary level. Contemporary Issues in Education Research (CIER), 3(3), 9-14.

Pólya, G. (1945) How to Solve It, Princeton University Press, Princeton, New Jersey

Schoenfeld, A. H. (1983). Problem solving in the mathematics curriculum: A report, recommendations, and an annotated bibliography. $A M C, 10,12$.

Shekoyan, V., \& Etkina, E. (2007, November). Introducing ill-structured problems in introductory physics recitations. In 2007 Physics Education Research Conference (Vol. 951, pp. 192-195).

Shereen, R. 2006. Teaching of Mathematics A. P.H. Publishing Corporation New Delhi India. P.136-176

Silver, E. A. (1997). Fostering creativity through instruction rich in mathematical 
problem solving and problem posing. ZDM, 29(3), 75-80.

Skinner, C.E. (1984). Educational Psychology fourth edition Pretice Hall of India (Pvt.). Ltd. New Delhi. India. P-529.

Sullivan, P. (2003). The Potential of Open-Ended Mathematics Tasks for Overcoming Barriers to Learning.

Wismath, S., Orr, D., \& Good, B. (2012). Metacognition: Student Reflections on Problem Solving.

$\mathrm{Wu}$, H. (1994). The role of open-ended problems in mathematics education. The Journal of Mathematical Behavior, 13(1), 115-128.

Yee, F. P. (2002). Using Short Open-ended Mathematics Questions to Promote Thinking and Understanding. In Proceedings of the 4 th International Conference on The Humanistic Renaissance in Mathematics Education, Palermo, Italy. 